Schwendel, Arved ORCID:

https://orcid.org/0000-0003-2937-1748, Death, R. G., Fuller, I. C. and Tonkin, J. D. (2011) A new approach to assess bed stability relevant for invertebrate communities in upland streams. River Research and Applications, 28 (10). pp. 1726-1739.

Downloaded from: http://ray.yorksj.ac.uk/id/eprint/2618/

The version presented here may differ from the published version or version of record. If you intend to cite from the work you are advised to consult the publisher's version: https://doi.org/10.1002/rra.1570

Research at York St John (RaY) is an institutional repository. It supports the principles of open access by making the research outputs of the University available in digital form. Copyright of the items stored in RaY reside with the authors and/or other copyright owners. Users may access full text items free of charge, and may download a copy for private study or non-commercial research. For further reuse terms, see licence terms governing individual outputs. Institutional Repository Policy Statement

\title{
RaY
}

Research at the University of York St John

For more information please contact RaY at ray@yorksj.ac.uk 
River Research and Applications

WILEY

\section{A new approach to assess bed stability relevant for invertebrate communities in upland streams}

\begin{tabular}{|r|l|}
\hline Journal: & River Research and Applications \\
\hline Manuscript ID: & RRA-10-0147.R1 \\
\hline Wiley - Manuscript type: & Research Article \\
\hline Date Submitted by the \\
Author: & $\mathrm{n} / \mathrm{a}$ \\
\hline Complete List of Authors: & $\begin{array}{l}\text { Schwendel, Arved; Massey University, Institute of Natural } \\
\text { Resources - Ecology } \\
\text { Death, Russell; Massey University, Institute of Natural Resources - } \\
\text { Ecology } \\
\text { Fuller, Ian; Massey University, Institute of Natural Resources - } \\
\text { Geography } \\
\text { Tonkin, Jonathan; Massey University, Institute of Natural Resources } \\
\text { - Ecology }\end{array}$ \\
\hline Keywords: & $\begin{array}{l}\text { bedload transport, lotic ecosystem, mountain stream, stream } \\
\text { ecology, substrate stability, tracer stone }\end{array}$ \\
\hline
\end{tabular}

\section{SCHOLARONE $^{\text {th }}$ Manuscripts}




\section{A new approach to assess bed stability relevant for invertebrate communities in upland streams}

Arved C. Schwendel, Ecology Group, Institute of Natural Resources, Massey

University, Private Bag 11222, Palmerston North 4442, New Zealand

Current address: College of Life and Environmental Sciences - Geography, University of Exeter, Exeter EX4 4RJ, UK

Email: A.Schwendel@exeter.ac.uk

Phone: +44 1392724488

Fax: +44 1392723342

Russell G. Death, Ecology Group, Institute of Natural Resources, Massey University, Palmerston North, New Zealand, Email: R.G.Death@massey.ac.nz

Ian C. Fuller, Physical Geography Group, Institute of Natural Resources, Massey University, Palmerston North, Email: I.C.Fuller@massey.ac.nz

Jonathan Tonkin, Ecology Group, Institute of Natural Resources, Massey University, Palmerston North, New Zealand, Email: J.Tonkin@massey.ac.nz

Running head: A new approach to assess bed stability

Keywords: bedload transport, lotic ecosystem, mountain stream, stream ecology, substrate stability, tracer stone 


\begin{abstract}
Composition and structure of lotic ecosystems can be affected by substrate instability. Consequently stream ecologists have used various methods to determine bed stability characteristics. However, the link between community composition and these measurements varies because benthic biota often respond to combinations of bed stability characteristics. This paper presents a protocol to determine reach-scale stream bed stability in mountain streams which is relevant for invertebrate communities (Stream Bed Stability for Invertebrates, SBSI). The approach is calibrated on community composition response to bed stability but does not measure any single bed stability characteristic per se. It consists of 13 parameters that are assessed once at each reach with minimal instrumentation and low interference with the substrate. These 13 parameters cover aspects of sediment supply from banks, transport capacity and substrate erodibility as well as effects of particle transport on channel bottom structures, substrate assemblage and single grains. Application of the SBSI protocol improved the relationship between bed stability and community diversity compared to when conventional bed stability measures were employed. The SBSI protocol provides a cost- and time-effective assessment method for bed stability and its application can facilitate research on invertebrate community response to physical disturbance.
\end{abstract}


Flow influences many important structural attributes of stream ecosystems such as substrate stability, habitat volume and channel morphology (Poff and Ward, 1989). Variation in discharge is recognised as one of the fundamental determinants of structure and function of benthic communities in lotic ecosystems (Resh et al., 1988; Reice et al., 1990; Lake, 2000; Death, 2008). Floods can cause movement of coarse bed substrate which can affect composition of periphyton (Biggs et al., 1999), invertebrate (Cobb et al., 1992; Death and Winterbourn, 1995; Holomuzki and Biggs, 2000), bryophyte (Suren and Duncan, 1999) and macrophyte communities (Riis et al., 2008). However, different groups of biota respond to different aspects of bed stability on a range of scales. For instance the reaction to patchy scour or fill varied between invertebrate taxa while on a larger scale stable patches might migitate the effects substrate instability (Matthaei and Townsend, 2000). Bed stability is a characteristic feature of alluvial channels comprising aspects like entrainment, transport and deposition of substrate as well as abrasion by suspended material on scales ranging from a single particle to an entire reach. These bed stability characteristics might affect sessile organisms in different ways than more mobile groups of biota (Downes, 1990; Englund, 1991; Holomuzki and Biggs, 2000; McAuliffe, 1984). Consequently some methods to quantify bed stability perform well with one group of organisms but show only a weak connection with other groups (Duncan et al., 1999; Schwendel et $a l ., 2011 \mathrm{a})$. This in turn is reflected in the wide variety of bed stability measurements used by stream ecologists to examine the effects of flow disturbance (Schwendel et al., 2010).

The effects of substrate movement on stream invertebrate communities via habitat alteration, displacement and death of individuals, and changes in their food sources are widely recognised (e.g. Townsend et al., 1997; Matthaei and Townsend, 2000; Effenberger et al., 2006; Death, 2008; Schwendel et al., 2011b). Different levels of bed stability, e.g. apparent in depth and pattern of disturbance or in transport distance of particles, are reflected in invertebrate community composition for instance via recolonisation abilities of individual taxa (Death, 2008). The methods employed to assess bed stability in relation to invertebrate community metrics are reviewed in Schwendel et al. (2010) and include calculation of critical shear stress (Newbury, 1984; Cobb et al., 1992; Death and Winterbourn, 1995), FST-hemispheres (Dittrich 
and Schmedtje, 1995; Merigoux and Doledec, 2004), scour chains (Palmer et al., 1992; Matthaei and Townsend, 2000; Effenberger et al., 2006), scour plates (Palmer et al., 1992), tracer stones (Death and Winterbourn, 1994; Townsend et al., 1997; Death and Zimmermann, 2005; Barquin and Death, 2006), morphological budgeting (Schwendel et al., 2011a) and the Pfankuch Stability Index (Pfankuch, 1975; Death and Winterbourn, 1995; Townsend et al., 1997; Death, 2002). Each of these methods can only assess a distinct set of bed stability characteristics and the strength of the relationship with invertebrate diversity and community composition varies (Schwendel et al., 2011a). The need of site specific calibration (e.g. bedload transport formulae and acoustics sensors) and interference with the substrate (e.g. scour plates and bedload traps) can constrain application for multi site studies and concomitant invertebrate sampling respectively (Schwendel et al., 2010). Insufficient spatial (e.g. bedload samplers) or temporal coverage (e.g. FST-hemispheres) for reach-wide, longterm bed stability assessment can be an additional problem. Further, time and cost constraints can often prevent application of elaborate methods. Visual surveys of stream bed properties such as the Pfankuch Stability Index can circumvent some of these limitations but they can potentially be biased by observers or regional factors such as substrate lithology.

Thus a technique that combines the strengths of elaborate bed stability measurements with the easy application of a visual approach would facilitate research on stream invertebrates and increase comparability between studies. Consequently, this paper presents a straightforward survey protocol specifically calibrated for the assessment of reach-scale stream bed stability relevant for invertebrate community composition (SBSI). It needs to be pointed out that the SBSI survey does not measure any single aspect of bed stability per se but determines a characteristic response of invertebrate community composition to a combination of bed stability characteristics. The SBSI was validated at independent sites using in situ marked tracer stones and the bottom component of the Pfankuch Index, two techniques that were shown to be well related to invertebrate community metrics (Schwendel et al., 2011a). Additionally the connection between bed stability measured with SBSI and community metrics was explored.

Application for the SBSI method may include scientific studies of disturbancediversity relationships and habitat characteristics as well as assessment of the potentially confounding effects of bed instability on invertebrate community 


\section{METHODS}

\section{Study sites}

Data for calibration and validation of SBSI protocol were collected between October 2007 and March 2010 from 54 mountain stream reaches in the southern part of the North Island of New Zealand. They were located in the axial Tararua $(\mathrm{n}=12)$ and Ruahine Ranges $(n=11)$, the Central Volcanic Plateau $(n=13)$ and around Mt. Egmont $(\mathrm{n}=18)$ (Figure 1). The former ranges consist of uplifted folded and faulted Mesozoic greywacke and argillite whereas the other mountains are composed of Quaternary andesitic volcanic deposits. Catchment vegetation was dominated by native broadleaf-podocarp forests, scrub and tussock grassland and anthropogenic influence is relatively small (e.g. $<0.1 \%$ urban land use, $0-45 \%$ non-intensive pasture and no infrastructure upstream of sites). Consequently water quality was expected to be relatively unimpaired. The studied stream reaches varied considerably in substrate assemblage, width, channel form (Table I) and sediment supply (Schwendel and Fuller, in press). Substrate composition ranged between gravels and cobbles although some sites contained a considerable proportion of boulders. Riparian vegetation was variable with native forest, willows and poplars, native scrub, non-intensive pasture, tussock and bare ground present. Some of the reaches were laterally confined by vegetated banks, whereas others migrated within a wide active channel zone.

\section{Invertebrate communities}

Five Surber samples $\left(500 \mu \mathrm{m}\right.$ mesh, $\left.0.1 \mathrm{~m}^{2}\right)$ were collected from riffles during periods of baseflow at least two weeks after the last spate to ensure a characteristic species assemblage was collected. Seasonal variability in New Zealand stream invertebrate communities is generally low (Towns, 1981; Winterbourn, 2000) however, this was tested and confirmed at 18 of the sites where samples were taken three times throughout the year (Schwendel et al., 2011a and J. Tonkin, unpublished data). Samples were stored in $4 \%$ formalin or $>60 \%$ isopropyl alcohol and later sorted. Very 
abundant taxa (>300 individuals per sample) were subsampled following Vinson and Hawkins (1996): samples expected to contain large numbers were divided in equal subsamples of which one was initially searched for invertebrates. Only those taxa which number of individuals did not exceed 300 in the first subsample were searched for in the second subsample. Invertebrates were identified to the lowest possible taxonomic level using the keys in McFarlane (1951), Winterbourn (1973), Towns and Peters (1996) and Winterbourn et al. (2006). Invertebrates were sampled where applicable from riffles because community composition there is likely to reflect gradations in substrate stability and on a larger scale instability in riffles affects also pools, e.g. via bedload transport.

\section{Periphyton and habitat parameters}

At each invertebrate sampling point depth, wetted stream width and near-bottom flow velocity were measured. The latter was recorded over $60 \mathrm{~s}$ with an electromagnetic flow meter (Model 801, Valeport Ltd., Devon, UK) $0.05 \mathrm{~m}$ above the stream bed. At each site $\mathrm{pH}$ and temperature corrected conductivity were measured using Eutech pHtestr2 and ECScan Low+ (Eutech Instruments, Singapore) respectively. Percentage aerial cover of riparian land use categories (native vegetation, pasture and willows) within a strip of approximately $5 \mathrm{~m}$ and the fraction of dry active channel bare of vegetation under base flow conditions was estimated visually.

Chlorophyll a pigment concentration on five gravel-sized stones that were collected beside invertebrate samples was assessed as a measure of periphyton biomass. The stones were transported in the dark in cooled stream water before storing them at $-18^{\circ} \mathrm{C}$. Pigments were extracted in $90 \%$ acetone for $18 \mathrm{~h}$ at $5^{\circ} \mathrm{C}$ in the dark before the chlorophyll a absorption was measured using a Cary 50 Conc UVVisible spectrometer (Varian, Mulgrave, Australia). Chlorophyll a pigment concentration was calculated (Steinman and Lamberti, 1996; APHA, 1998) and corrected for stone surface area which was estimated based on measurement of the a-, b- and c-axes of the gravels with a sliding calliper following Graham et al. (1988).

Substrate composition of riffles was assessed by measuring the b-axis of $>100$ randomly collected particles (Wolman, 1954) and classifying them according to a modified Wentworth scale. 


\section{Bed stability}

Substrate stability was assessed with two established reference measures: tracer particles and the Pfankuch Stability Index. For the development of the new approach a set of 38 candidate variables (Table II) were selected from a large array of parameters potentially related to stream bed stability (Knighton, 2008; Petts and Foster, 1985) in respect to importance and practicability of assessment with minimal instrumentation in the field. These candidate variables were evaluated at stream sections with a length of approximately $5-7$ times stream width to include, where present at least one rifflepool unit (Keller and Melhorn, 1978).

Candidate variables are associated with the riparian environment (denoted A), the cross (B) and longitudinal profile (C) of the channel, the channel bottom structure (D) and the substrate (E). The density and composition of the riparian vegetation within a 5 m-strip along the active channel zone (A1, A3) reflects bank stabilisation by roots, pressure from land use and frequency and magnitude of flood disturbance. Together with bank erosion (B2) and deposition of derived fine sediments (B3) these parameters indicate sediment supply from banks and slopes. These processes influence substrate characteristics (E3-6) which can be relevant for bed stability. Transport capacity is assessed in terms of available potential energy (slope) (C1), expenditure on roughness elements (D6), channel adjustments (C2, D4) and flood regime (A2). The channel dynamics resulting from sediment supply and transport capacity are reflected in channel form (B1), structures (D1, D3-5), aquatic vegetation (D2) and substrate characteristics (E1-4, E7). Additionally lithology of the substrate, weather (sunny, overcast or rain) and state of the floodplain substrate (dry or wet) were recorded because these factors could potentially interfere with visual evaluation methods such as the Pfankuch Index (A. C. Schwendel, unpublished data).

Tracer particles were used to assess stream bed stability. Five randomly selected tracer stones in each of three size classes $\left(\mathrm{D}_{50}, \mathrm{D}_{70}\right.$ and $\left.\mathrm{D}_{90}\right)$ were marked with radiofrequency identification (RFID) tags (23 mm glass tags, Texas Instruments, Dallas, USA) which were attached in situ to stones in riffles using wet curing epoxy-concrete (K273, Nuplex Construction Products, Hamilton, New Zealand). When high turbulence or fast flow velocity prevented underwater application (11\% of particles), stones were removed from the river bed for tag attachment and afterwards carefully re-embedded. The percentage of entrained in situ-marked tracer stones and re- 
embedded tracers was significantly correlated (Spearman-rank correlation, $R=0.70$, $\mathrm{df}=26, \mathrm{p}=0.0001)$. Relocation and identification of each tracer stone was carried out contactless using a portable antenna and datalogger (OregonRFID, Portland, USA). Initial and subsequent positions of tagged stones were surveyed using high precision differential GPS or marked on riparian vegetation and stable banks. Relocation surveys took place approximately every two months or after high discharge events over a total period of six months. The entire bed and active channel downstream of the last position of each tracer particle was searched intensively to the next local sediment trap (e.g. riffle) beyond a minimal distance of $50 \mathrm{~m}$. Stones that could not be recovered were assigned a travel distance of $50 \mathrm{~m}$. Although this was less then usually searched it accounted for tracers lost by deep burial $(>0.6 \mathrm{~m})$, storage in inactive parts of the floodplain, tag damage and malfunction. The travelled distance of the tracer particles was converted to an index of bed stability (TTM = sum of tracer movement) using the following approach:

$\mathrm{TTM}=\left(\mathrm{d}_{50} * \mathrm{~s}_{50} / \mathrm{n}_{50}+\mathrm{d}_{70} * \mathrm{~s}_{70} / \mathrm{n}_{70}+\mathrm{d}_{90} * \mathrm{~s}_{90} / \mathrm{n}_{90}\right) /\left(\mathrm{d}_{50}+\mathrm{d}_{70}+\mathrm{d}_{90}\right)$

The sum of the moved distance s of stones of a size class between the surveys is divided by the counted recoveries $n$ and weighted by the geometric mean particle size $\mathrm{d}$ of that class.

As a second independent measure of bed stability the bottom component of the Pfankuch Stability Index (BCP) (Pfankuch, 1975) was employed once at each site. The bottom component was preferred over the total index because in previous studies it showed a better relationship with other measures of bed stability (Death and Winterbourn, 1994) and is well related to biological data (Death and Winterbourn, 1995; Suren, 1996). It involves allocation of an observer's subjective visual evaluation of six attributes, including substrate brightness, angularity, consolidation of particles, percentage of stable materials, evidence of scouring and state of clinging aquatic vegetation, to four predetermined categories to which scores are weighted according to their perceived importance. The sum of the scores results in a stability index, where high values represent low stability.

Data analysis 
The collected data were examined in four steps: (1) analysis of invertebrate community composition and structure, (2) development of the SBSI protocol, (3) exploration of the relationship between SBSI, other measures of bed stability and community metrics and (4) validation of the SBSI protocol at independent sites in respect to other bed stability measures and relevance for invertebrate communities.

The composition of the invertebrate community at 46 calibration sites (Figure 1) was explored with non-metric multidimensional scaling (NMDS) in PC-ORD 5.0 (MjM Software, Gleneden Beach, USA) using standardised (by maximum) invertebrate taxa abundance. Association of the derived axis scores with measured environmental parameters and selected variables from the Freshwater Environments of New Zealand (FWENZ) database (Wild et al., 2005) was assessed using Pearson's correlation. The axis that was best correlated to conventional bed stability measures TTM and BCP was selected for calibration of the SBSI. Community diversity (Brillouin Index), taxa number, rarefied taxa number (for 200 individuals following Sanders (1968) and Hurlbert (1971)) and mean number of individuals per $0.1 \mathrm{~m}^{2}$ were calculated for all sites in PRIMER v6 (Plymouth Marine Laboratory, Plymouth, UK).

The SBSI was developed with linear best subset regression (Statistix 9.0, Analytical Software, Tallahassee, USA) using the selected NMDS axis as dependent variable and the 38 parameters assessed in the field (Table II) as independent variables. Adjusted $\mathrm{R}^{2}$, residual mean square error, Mallows' $\mathrm{Cp}$, predicted residual sum of squares and Akaike's Information Criterion for small samples (AICc) were used to compare models.

The relationship between the SBSI site scores, bed stability measured with tracer stones and the bottom component of the Pfankuch Index, and invertebrate community metrics was assessed with Spearman rank correlation to account for the non-normal distribution of variables. This was accomplished for the 46 sites used for SBSI calibration to show the relevance of the SBSI for invertebrate communities and separately for the eight validation sites. The latter consisted of four randomly selected reaches in each of the two bedrock regions (volcanic and sedimentary) in order to account for variations in shape and colour of the substrate. Significance from the multiple correlations was adjusted using false discovery rate correction (Benjamini and Hochberg, 1995). 


\section{Invertebrate community}

A total of 127 invertebrate taxa were collected across the 46 SBSI calibration sites with a mean number of individuals per $0.1 \mathrm{~m}^{2}$ of 194 consisting of on average 33 taxa. Overall Trichoptera comprised the largest number of taxa (35\%), followed by Diptera (25\%) but the samples were numerically dominated by Ephemeroptera larvae (45\% of individuals) of which Deleatidium was most common (100\% of sites) and abundant (42\% of individuals).

Ordination (2D stress 0.16 ) revealed that only one axis was strongly correlated with bed stability measured with tracer stones and the bottom component of the Pfankuch Index (Table III). This axis was also associated with periphyton biomass and the fraction of the active channel bare of vegetation (Figure 2). It was subsequently used to calibrate the SBSI. Sites associated with low bed stability were found in the Ruahine Ranges and around Mt. Egmont and were dominated by Deleatidium. In contrast very stable sites were located mostly on the Central Plateau and had a richer fauna and higher number of individuals.

\section{SBSI protocol}

Any intercorrelated variables of assessed reach properties were removed from further analysis (Table II). Weather and substrate surface wetness were not significantly correlated with other variables but substrate lithology (andesite and greywacke) was significantly correlated to grain angularity (E11) (Spearman's R 0.82, df $=45, \mathrm{p}=$ $0.0001)$. Andesitic stones were more rounded than greywacke clasts prior to fluvial transport. Consequently scores for grain angularity were raised by one class at sites with greywacke dominated substrate. Best subset regression, using the NMDS axis best correlated to bed stability measures as dependent variable and the refined set of reach properties as independent variables, led to the identification of an optimal model (Table IV). This model of stream bed stability relevant for invertebrates (SBSI) comprises 13 variables which reflect mostly direct effects of channel dynamics observed on the banks and at the channel bottom. Sediment supply and transport capacity are represented with two variables each which are assessed on the banks and the longitudinal channel profile. Substrate parameters (size and compaction) 
constitute a second group mirroring effects of sediment dynamics such as sorting. Low variance inflation factors (VIF) indicated that collinearity between the variables is low.

Based on the regression model a field sheet (Appendix 1) was designed that facilitates recording of the variables and allows with the help of a pocket calculator rapid on-site assessment of bed stability. Channel, bank and substrate properties are to be recorded, noted in relevant fields and multiplied with their respective coefficient. The sum for each compartment (e.g. banks, longitudinal profile, channel bottom and substrate) is recorded on the right hand side of the sheet and this column is than added up to result in the SBSI site score.

\section{Bed stability and community metrics}

Correlation between the SBSI site scores and community diversity (Brillouin Index), taxa number, rarefied taxa number and mean number of individuals was highly significant (Table V). These community metrics were also correlated with bed stability measured with tracers (except taxa number) or the bottom component of the Pfankuch Index but the connection was always weaker than with the SBSI.

The three measures of bed stability were intercorrelated with the strongest relationship apparent between the bottom component of the Pfankuch Index and SBSI site scores (Table VI).

\section{Validation at independent sites}

At eight randomly selected sites a linear relationship was found between bed stability assessed with the bottom component of the Pfankuch Index and the SBSI protocol (Table VI). In contrast the tracer measure was not correlated with any of the two former, however, correlation coefficients were similar or higher than at the sites used for SBSI calibration and the failure of detection of a significant relationship might be due to the low number of sites. Correlation between the Brillouin Index and SBSI site scores was stronger than with any of the other bed stability measures (Table V). In contrast taxa number, rarefied taxa number and the mean number of individuals were slightly better related to the bottom component of the Pfankuch Index. 


\section{DISCUSSION}

The presented protocol for assessment of bed stability relevant for invertebrates (SBSI) produces site scores highly related to invertebrate community diversity and structure. This connection is stronger than that of any traditional bed stability measure with community metrics at the calibration sites. The SBSI method is calibrated on the response of invertebrate communities, signified by a NMDS axis, to varying degrees of bed stability as measured with traditional techniques and compares well to the NMDS calibration axis (Table VI, Figure 3). The NMDS axis used for calibration of the SBSI is strongly associated with bed stability measures and periphyton biomass. Periphyton as a potential food source for invertebrates influences invertebrate community composition (Death, 2002) but biomass itself is affected by bed movement and can consequently be seen as a proxy for bed stability. The link of the NMDS calibration axis with the percentage of bare active channel reflects the flood regime which influences bed stability. Lack of vegetation on the banks can indicate regular inundation with flows competent to strip vegetation and to prevent perennial plant growth. Alternatively it can be caused by active bank erosion during lower discharges when undercutting of banks can lead to failure. This reflects a high degree of channel activity and sediment input and accordingly bed disturbance. Hence it is reasonable to interpret the NMDS axis as being dominated by bed stability.

Validation at independent sites showed the applicability of the SBSI approach and its relevance for invertebrates. Connection with community diversity is improved when the SBSI is used compared to other bed stability measures but the bottom component of the Pfankuch Index performs slightly better with number of taxa and individuals (Figure 4). However, the SBSI approach can account for regional variation in parameters such as lithology and should be less affected by observer subjectivity than the purely visual assessment of the Pfankuch Index.

The parameters of the SBSI model are summarised in Table VII. Theoretically the total SBSI score ranges between 19 (stable) and 201 (unstable) when extreme values for all parameters are assumed. However, the calibration sites which, according to the bed stability measurements, include both very stable and unstable reaches, cover a range of only 62 to 88 . Thus values higher than 80 represent sites with low bed stability whereas SBSI smaller than 70 indicates high bed stability. The substrate sand fraction and homogeneity are potentially the most powerful parameters but their 
extreme values seldom occur in mountain streams. At the calibration sites bank vegetation cover and abundance of multiple barforms had the highest mean scores (10.8 and 9.1 respectively) while slope, area of multiple barforms and sand fraction achieved lowest mean scores $(<2.3)$. In the following section for each parameter the relation to bed stability is explored and assessment in the field with the help of the provided field sheet (Appendix 1) is described.

Friction slope determines the total energy available for transport and entrainment of particles in a stream. Water surface or stream bed gradient is often used a as a surrogate because it is easier to measure (Schwendel et al., 2010). When the ratio of flow depth to roughness element height is high (e.g. during high discharge) this is an acceptable first-order approximation. Bed slope can be estimated in the field, if necessary with the help of an Abney level.

The active channel includes the zone that is dry at baseflow stage but is subject to regular inundation. It is well coupled to the channel and it is involved in processes of sediment transport. In the field this zone can be determined by the absence or scarcity of perennial vegetation and the presence of recent flood debris. The ratio of the active channel width to wetted baseflow channel width is low (e.g. close to 1) for hydrologically stable streams with small variation in flows (e.g. lake fed). With increasing frequency and magnitude of floods a higher ratio is expected although local geomorphology can interfere (e.g. narrow valleys, bedrock constrictions and bank composition). Both this parameter and stream bed slope quantify potential transport capacity and are expressed on a continuous scale. Considering the potential range of values, bed slope has much less weight than the active channel to baseflow channel width ratio in the regression model.

The sediment supply from banks and lateral channel erosion is represented by the categorical parameter bank erosion. It is evaluated in the field on a scale ranging from none over weak and moderate to strong. Strong bank erosion means that eroded surfaces or collapsed banks are present throughout the reach and that lateral erosion is severe. Moderate bank erosion depicts a state where either light and discontinuous bank erosion is common or locally bank erosion is strong. The category "weak bank erosion" is chosen when only patchy and light bank erosion occurs. Extrinsic causes for bank collapse such as trampling cattle or human interference are included in this parameter and are not separately assessed. 
The percentage of riparian vegetation cover of the upper banks (above bankfull stage) specifies average vegetation density of the understorey (e.g. stems per $\mathrm{m}^{2}$ ), not the canopy cover along both sides of the reach. It was expected to be positively related to bed stability because vegetation reduces surface erosion and dense roots stabilise the banks. However, regression showed an inverse relationship to bed stability which can be explained by land use, altitude aspects and bank composition. The sites with low bank vegetation cover were either in high altitude locations on the Central Volcanic Plateau or natural vegetation was scarce. Anthropogenic land use practices like forestry or gravel mining on floodplains can cause low density of bank vegetation. They are only profitable on relatively stable ground thus reflecting bank stability. Altitude mirrors catchment size and is thus related to stream power. Hence high altitude sites above the tree line with low vegetation cover have usually more stable upper banks than low altitude sites. This parameter combines these two causes of bank vegetation cover while bank protection by roots is obviously of less importance on the infrequent flood-affected upper banks. We used an accuracy of 5\% for bank cover estimations.

Substrate size distribution reflects erosion, sedimentation and transport processes. Fine particles require less shear force for selective entrainment than coarse grains. Hiding and protrusion effects can prevent selective entrainment but visual surface substrate assemblage assessment does usually capture only patches dominated by sand and not hiding sand grains between larger particles. Thus the percentage of sand and smaller grain sizes present and the associated low critical shear stress can indicate high sediment mobility given sufficient transport capacity. Erosion and sedimentation of sandy substrate and associated changes in habitat can cause shifts in invertebrate community composition (Palmer et al., 1992; Downes et al., 2006).

Substrate size homogeneity can be caused by sorting (e.g. downstream fining) but depends also on catchment substrate lithology and sediment sources (reworking of older alluvial deposits, hillslope collapses or fresh tributary inputs). However, in mountain streams where substrate variety is usually limited by catchment size, sorting can be instrumental for substrate size composition. Because sorting processes require substrate movement the parameter "substrate homogeneity" is positively related to instability. In the field it requires estimation of the percentage cover of the size classes silt $(<0.063 \mathrm{~mm})$, sand $(0.063 \mathrm{~mm}-2 \mathrm{~mm})$, gravel $(2 \mathrm{~mm}-64 \mathrm{~mm})$, cobble $(64 \mathrm{~mm}$ 
$-256 \mathrm{~mm})$ and boulder $(>256 \mathrm{~mm})$. Then the aerial cover fraction of the dominant size class is divided by the number of classes present.

Packing and compaction of particles is highly developed in stable substrate channels. It can be an effect of incompetent flows or lack of sediment supply. This parameter should not be confounded with overlap of particles because of the stone shape of some lithologies. It can easily be tested by walking in the bed and four categories are distinguished. Tight packing means that in the entire channel stones move only minimally when full body weight is applied and includes bedrock. Wedged packing depicts conditions where only parts of the channel have tight packing or where the entire substrate moves under the foot but does not principally change position (e.g. is entrained afterwards). The "moderately loose" category includes a mix of all four categories throughout the channel skewed towards looser conditions. Stones may change position when stepped on but should not be entirely dislodged. Loose packing means that the foot sinks into the substrate and particles move easily.

The categorical parameter "Constitution of particle surface" has been modified from the categories of brightness defined by Pfankuch (1975). It incorporates surface roughness and brightness which can be effects of particle movement. However, it needs to be distinguished between different lithologies (e.g. limestone and volcanic rocks) which have varying spectra of colours and brightness. Particles of different geological origin can have variable surface roughness after the same transport length. Stains and plant growth on stones are dependent on temperature, light, nutrient levels and mineralisation. It is also advisable to allow for weather conditions and surface moisture when stones on the floodplain are investigated: Wet surfaces on a rainy day can appear much duller than in dry and sunny conditions. The categories range from more than $95 \%$ of stained particles with considerable organic film and growth, over " $65-95 \%$ dull" and " $35-65 \%$ dull" to less than $35 \%$ dull.

The parameter "Grain angularity" was also adopted from the Pfankuch Index. It ideally expresses the amount of work performed on a particle during fluvial transport but the characteristic depends very much on lithology in terms of hardness, cleavability, stratification and mineral content as well as distance from source. Thus adjustment of the scores of sharp and angular rock types such as mudstone greywacke to the scores of particles that are already rounded prior to fluvial transport (e.g. some volcanic rocks) by the observer is recommended. The categories include particles well rounded in all dimensions with smooth surfaces, corners and edges well rounded in 
two dimensions, corners and edges rounded combined with flat surfaces and sharp edges and corners with roughened surfaces.

The percentage of reworked area describes the amount of obvious recent erosion (e.g. bright sections) and sedimentation (bars of fines, filled pools) of the channel bottom. A fraction of more than $80 \%$ is rated as very high, $50-80 \%$ as high, $20-$ $49 \%$ as intermediate and less than $20 \%$ as low.

Multiple barforms are a feature of dynamic channels able to adjust to changing sediment supply and floods. However, over short-term they can be relatively stable channel structures creating various habitats and providing potential refugia during smaller spates. Surprisingly, the number of multiple barforms is positively related to bed stability in the SBSI model which might reflect habitat heterogeneity. In contrast their size as a fraction of the total bed area decreases with SBSI bed stability because large areas of multiple barforms indicate substantial channel dynamics. The number of multiple barforms is classified in six categories which are indexed from 0 to 5 .

Bedform clusters locally influence flow turbulence causing expenditure of energy which is not available to entrain substrate. They are commonly thought to be resistant to entrainment during high-discharge events (de Jong, 1992; Reid et al., 1992) but depending on flood magnitude bed form clusters can be as unstable as single surface stones (Matthaei and Huber, 2002). Thus their suitability as refugia for invertebrates and periphyton varies and they do not necessarily support richer invertebrate faunas because of increased habitat heterogeneity (Biggs et al., 1997; Francoeur et al., 1998; Matthaei and Huber, 2002). For the SBSI protocol abundance of bedform clusters is estimated in the field visually and categorised in four classes ranging from none to abundant (e.g. $>5 \%$ aerial cover).

\section{CONCLUSIONS}

The method presented here for reach-scale assessment of bed stability relevant for invertebrate communities in upland streams seeks to combine statistically derived relationships between bed stability characteristics and the invertebrate community and causal connections. This distinguishes it from other approaches which aim to measure characteristics of bed stability per se but often are not very well related to responses of different groups of biota. The SBSI protocol provides a similar or stronger connection with community diversity and composition than traditional bed stability 


\section{REFERENCES}

APHA. 1998. Standard methods for the examination of water and wastewater. 20th ed. American Public Health Association. American Water Works Association, Water Pollution Control Federation.: Washington D.C.

Barquin J, Death RG. 2006. Spatial patterns of macroinvertebrate diversity in New Zealand springbrooks and rhithral streams. Journal of the North American Benthological Society 25: 768-786.

Benjamini Y, Hochberg Y. 1995. Controlling the False Discovery Rate. Journal of Royal Statistical Society. Series B (Methodological) 57: 289-300.

Biggs BJE, Duncan MJ, Francoeur SN, Meyer WD. 1997. Physical characterisation of microform bed cluster refugia in 12 headwater streams, New Zealand. New Zealand Journal of Marine and Freshwater Research 31: 413-422.

Biggs BJF, Smith RA, Duncan MJ. 1999. Velocity and sediment disturbance of periphyton in headwater streams: biomass and metabolism. Journal of the North American Benthological Society 18: 222-241. 
Cobb DG, Galloway TD, Flannagan JF. 1992. Effects of discharge and substrate stability on density and species composition of stream insects. Canadian Journal of Fisheries and Aquatic Sciences 49: 1788-1795.

Death RG. 2002. Predicting invertebrate diversity from disturbance regimes in forest streams. Oikos 97: 18-30.

Death RG. 2008. Effects of floods on aquatic invertebrate communities. In: Lancaster J, Briers RA (Editors). Aquatic Insects: Challenges to Populations. CAB International, Wallingford, Oxfordshire, pp. 103 - 121.

Death RG, Winterbourn MJ. 1994. Environmental stability and community persistence - a multivariate perspective. Journal of the North American Benthological Society 13: 125-139.

Death RG, Winterbourn MJ. 1995. Diversity patterns in stream benthic invertebrate communities - the influence of habitat stability. Ecology 76: 1446-1460.

Death RG, Zimmermann EM. 2005. Interaction between disturbance and primary productivity in determining stream invertebrate diversity. Oikos 111: 392-402.

de Jong C. 1992. A reappraisal of the significance of obstacle clasts in cluster bedform dispersal. Earth Surface Processes and Landforms 16: 737-744.

Dittrich A, Schmedtje U. 1995. Indicating shear-stress with FST-hemispheres - effects of stream-bottom topography and water depth. Freshwater Biology 34: 107121.

Downes BJ. 1990. Patch dynamics and mobility of fauna in streams and other habitats. Oikos 59: 411-413.

Downes BJ, Lake PS, Glaister A, Bond NR. 2006. Effects of sand sedimentation on the macroinvertebrate fauna of lowland streams: are the effects consistent? Freshwater Biology 51: 144-160.

Duncan MJ, Suren AM, Brown SLR. 1999. Assessment of streambed stability in steep, bouldery streams: development of a new analytical technique. Journal of the North American Benthological Society 18: 445-456.

Effenberger M, Sailer G, Townsend CR, Matthaei CD. 2006. Local disturbance history and habitat parameters influence the microdistribution of stream invertebrates. Freshwater Biology 51: 312-332.

Englund G. 1991. Effects of disturbance on stream moss and invertebrate community structure. Journal of the North American Benthological Society 10: 143-153. 
Francoeur SN, Biggs BJE, Lowe RL. 1998. Microform bed clusters as refugia for periphyton in a flood-prone headwater stream. New Zealand Journal of Marine and Freshwater Research 32: 363-374.

Graham AA, McCaughan DJ, McKee FS. 1988. Measurement of surface area of stones. Hydrobiologia 157: 85-87.

Holomuzki JR, Biggs BJF. 2000. Taxon-specific responses to high-flow disturbance in streams: implications for population persistence. Journal of the North American Benthological Society 19: 670-679.

Hurlbert SH. 1971. The non-concept of species diversity: a critique and alternative parameters. Ecology 52: 577-586.

Keller EA, Melhorn WN. 1978. Rhythmic spacing and origin of pools and riffles. Geological Society of America Bulletin 89: 723-730.

Knighton D. 2008. Fluvial forms and processes: a new perspective. Arnold: London Lake PS. 2000. Disturbance, patchiness, and diversity in streams. Journal of the North American Benthological Society 19: 573-592.

Matthaei CD, Huber H. 2002. Microform bed clusters: are they preferred habitats for invertebrates in a flood-prone stream? Freshwater Biology 47: 2174-2190.

Matthaei CD, Townsend CR. 2000. Long-term effects of local disturbance history on mobile stream invertebrates. Oecologia 125: 119-126.

McAuliffe JR. 1984. Commpetition for space, disturbance, and the structure of a benthic stream community. Ecology 65: 894-908.

McFarlane AG. 1951. Caddisfly larvae (Trichoptera) of the family Rhyacophilidae. Records of the Canterbury Museum 5: 267-289.

Merigoux S, Doledec S. 2004. Hydraulic requirements of stream communities: a case study on invertebrates. Freshwater Biology 49: 600-613.

Newbury RW. 1984. Hydrologic determinants of aquatic insect habitats. In: Resh VH, Rosenberg DM (Editors). The Ecology of Aquatic Insects. Praeger Publishers, New York, pp. 323-357.

Palmer MA, Bely AE, Berg KE. 1992. Response of invertebrates to lotic disturbance a test of the hyporheic refuge hypothesis. Oecologia 89: 182-194.

Petts GE, Foster IDL. 1985. Rivers and landscape. Edward Arnold: London Pfankuch DJ. 1975. Stream reach inventory and channel stability evaluation., U.S.D.A. Forest Service, Region 1, Missoula, Montana. 
Poff NL, Ward JV. 1989. Implications of streamflow variability and predictability for lotic community structure - a regional-analysis of streamflow patterns. Canadian Journal of Fisheries and Aquatic Sciences 46: 1805-1818.

Reice SR, Wissmar RC, Naiman RJ. 1990. Disturbance regimes, resilience, and recovery of animal communities and habitats in lotic ecosystems.

Environmental Management 14: 647-659.

Reid I, Frostick LE, Brayshaw AC. 1992. Microform roughness elements and the selective entrainment of particles in gravel-bed rivers. In: Billi P, Hey RD, Thorne CR, Tacconi P (Editors). Dynamics of Gravel-Bed Rivers. Wiley, Chichester, pp. 253-275.

Resh VH, Brown AV, Covich AP, Gurtz ME, Li HW, Minshall GW, Reice SR, Sheldon AL, Wallace JB, Wissmar RC. 1988. The role of disturbance in stream ecology. Journal of the North American Benthological Society 7: 433-455.

Riis T, Suren AM, Clausen B, Sand-Jensen K. 2008. Vegetation and flow regime in lowland streams. Freshwater Biology 53: 1531-1543. DOI: 10.1111/j.13652427.2008.01987.x.

Sanders HL. 1968. Marine benthic diversity: a comparative study. American Naturalist 102: 243-282.

Schwendel AC, Death RG, Fuller IC. 2010. The assessment of shear stress and bed stability in stream ecology. Freshwater Biology 55: 261-281. DOI: 10.1111/j.1365-2427.2009.02293.x.

Schwendel AC, Death RG, Fuller IC, Joy MK. 2011a. Linking disturbance and stream invertebrate communities - how best to measure bed stability. Journal of the North American Benthological Society 30: 11-24. DOI: 10.1899/09-172.1.

Schwendel AC, Fuller IC. in press. Connectivity in forested upland catchments and associated channel dynamics: The Ruahine Range. Journal of Hydrology (NZ).

Schwendel AC, Joy MK, Death RG, Fuller IC. 2011b. A macroinvertebrate index to assess stream-bed stability. Marine and Freshwater Research 62: 30-37. DOI: 10.1071/MF10137.

Steinman AD, Lamberti GA. 1996. Biomass and Pigments of Benthic Algae. In: Hauer FR, Lamberti GA (Editors). Methods in Stream Ecology. Academic Press, San Diego, pp. 295 - 313. 
Suren AM. 1996. Bryophyte distribution patterns in relation to macro-, meso-, and micro-scale variables in South Island, New Zealand streams. New Zealand Journal of Marine and Freshwater Research 30: 501-523.

Suren AM, Duncan MJ. 1999. Rolling stones and mosses: effect of substrate stability on bryophyte communities in streams. Journal of the North American Benthological Society 18: 457-467.

Towns DR. 1981. Life histories of benthic invertebrates in a kauri forest stream in Northern New Zealand. Australian Journal of Marine and Freshwater Research 32: 191-211.

Towns DR, Peters WL. 1996. Leptophlebiidae (Insecta: Ephemeroptera). Fauna of New Zealand, 36. Manaaki Whenua Press: Lincoln.

Townsend CR, Scarsbrook MR, Doledec S. 1997. Quantifying disturbance in streams: alternative measures of disturbance in relation to macroinvertebrate species traits and species richness. Journal of the North American Benthological Society 16: $531-544$.

Vinson MR, Hawkins CP. 1996. Effects of sampling area and subsampling procedure on comparisons of taxa richness among streams. Journal of the North American Benthological Society 15: 392-399.

Wild M, Snelder TH, Leathwick JR, Shankar U, Hurren H. 2005. Environmental variables for the freshwater environments of New Zealand river classification, NIWA, Christchurch.

Winterbourn MJ. 1973. A guide to the freshwater Molluscaa of New Zealand. Tuatara 20: 141-159.

Winterbourn MJ. 2000. Stream communities and ecosystem processes. In: Collier KJ, Winterbourn MJ (Editors). New Zealand stream invertebrates: Ecology and implications for management. NZ Hydrological Society, Christchurch, pp. 13.113.14 .

Winterbourn MJ, Gregson KLD, Dolphin CH. 2006. Guide to the aquatic insects of New Zealand. Bulletin of the Entomological Society of New Zealand 14. Entomological Society of New Zealand: Auckland

Wolman MJ. 1954. A method of sampling coarse river bed material. American Geophysical Union Transactions 35: 951-956. 
Table I. Abiotic characteristics of the study sites assessed between October 2007 and

March 2010. Depth, width, velocity, conductivity, temperature and $\mathrm{pH}$ measurements are averaged from 5 readings taken concomitant with invertebrate sampling, TTM is an index of bed stability calculated from the movement of in situ marked tracer stones. Sites used for validation are in italics.

\begin{tabular}{|c|c|c|c|c|c|c|c|c|c|}
\hline site & $\begin{array}{l}\text { Stream } \\
\text { order } \\
\text { (Strahler } \\
1952)\end{array}$ & $\begin{array}{l}\text { Mean } \\
\text { depth } \\
\text { (m) }\end{array}$ & $\begin{array}{l}\text { Mean } \\
\text { width } \\
\text { (m) }\end{array}$ & $\begin{array}{l}\text { Mean } \\
\text { flow } \\
\text { velocity } \\
\left(\mathrm{m}^{*} \mathrm{~s}^{-1}\right)\end{array}$ & $\begin{array}{l}\text { Mean } \\
\text { conductivi } \\
\text { ty } \\
\left(\mu \mathrm{S}^{*} \mathrm{~cm}^{-1}\right)\end{array}$ & $\begin{array}{l}\text { Mean } \\
\text { temper } \\
\text { ature } \\
\left({ }^{\circ} \mathrm{C}\right)\end{array}$ & $\begin{array}{l}\text { Mean } \\
\text { pH }\end{array}$ & $\begin{array}{l}\text { Substra } \\
\text { te } \mathrm{D}_{50} \\
(\mathrm{~mm})\end{array}$ & TTM \\
\hline \multicolumn{10}{|l|}{ Tararua Range } \\
\hline Waitohu & 4 & 0.20 & 6.8 & no data & 84 & 11.5 & 7.5 & 86 & 39.94 \\
\hline Waiotauru & 5 & 0.26 & 17.4 & 0.716 & 68 & 11.3 & 7.7 & 84 & 38.57 \\
\hline Waikawa & 4 & 0.18 & 6.1 & no data & 76 & 13.2 & 7.5 & 99 & 36.78 \\
\hline Panatewaewae & 3 & 0.11 & 7.0 & no data & 74 & 13.1 & 7.6 & 103 & 31.21 \\
\hline Kiriwhakapapa & 3 & 0.15 & 6.5 & 0.603 & 64 & 9.7 & 7.2 & 59 & 20.43 \\
\hline Ohau & 4 & 0.24 & 14.0 & 0.694 & 72 & 12.7 & 7.6 & 64 & 14.30 \\
\hline Pukeatua & 3 & 0.18 & 9.7 & 0.720 & 80 & 12.4 & 7.7 & 84 & 12.50 \\
\hline Makahika & 4 & 0.17 & 6.3 & no data & 66 & 19.4 & 7.4 & 82 & 11.18 \\
\hline Mangatainoka & 4 & 0.17 & 11.7 & 0.694 & 52 & 13.3 & 7.1 & 108 & 7.67 \\
\hline Rawnsley & 2 & 0.11 & 5.1 & 0.422 & 48 & 13.5 & 6.9 & 159 & 4.74 \\
\hline Tokomaru & 4 & 0.14 & 14.6 & 0.707 & 81 & 17.5 & 6.9 & 85 & 3.07 \\
\hline Kahuterawa & 4 & 0.15 & 3.5 & 0.616 & 68 & 14.1 & 6.5 & 85 & 0.06 \\
\hline \multicolumn{10}{|l|}{ Ruahine Range } \\
\hline Waipawa & 3 & 0.20 & 5.4 & 1.000 & 103 & 8.8 & 8.2 & 59 & 79.56 \\
\hline Tamaki & 2 & 0.17 & 3.3 & 0.811 & 64 & 10.8 & 7.6 & 35 & 64.46 \\
\hline Mangapuaka & 2 & 0.09 & 2.3 & 0.584 & 69 & 8.6 & 6.7 & 28 & 21.51 \\
\hline Konewa & 3 & 0.10 & 6.5 & 0.575 & 133 & 13.0 & 7.5 & 72 & 15.36 \\
\hline Rokaiwhana & 3 & 0.22 & 3.1 & 0.887 & 66 & 14.7 & 7.1 & 58 & 14.96 \\
\hline Makawakawa & 4 & 0.21 & 27.6 & 0.630 & 58 & 14.3 & 7.0 & 83 & 12.03 \\
\hline Raparapawai & 3 & 0.17 & 7.0 & 0.931 & 72 & 13.3 & 7.3 & 84 & 8.44 \\
\hline Makiekie & 2 & 0.19 & 5.7 & 0.646 & 51 & 10.9 & 7.3 & 109 & 4.86 \\
\hline Coppermine & 3 & 0.13 & 4.4 & 0.592 & 90 & 13.5 & 7.4 & 51 & 4.43 \\
\hline Manawatu & 3 & 0.20 & 4.3 & 0.603 & 66 & 9.4 & 7.8 & 65 & 3.85 \\
\hline Cone & 2 & 0.16 & 4.5 & 0.588 & 50 & 11.0 & 7.2 & 107 & 0.53 \\
\hline \multicolumn{10}{|l|}{ Central Plateau } \\
\hline Mangatoetoenui & 4 & 0.26 & 8.6 & 0.597 & 139 & 7.1 & 8.0 & 97 & 18.70 \\
\hline Waikato & 3 & 0.14 & 3.2 & no data & 66 & 10.0 & 7.8 & 18 & 11.38 \\
\hline Te Piripiri & 3 & 0.19 & 2.0 & 0.742 & 69 & 8.5 & 7.7 & 35 & 2.09 \\
\hline Wahianoa & 3 & 0.26 & 6.3 & 0.967 & 70 & 12.8 & 7.4 & 145 & 1.73 \\
\hline Whakapapaiti & 4 & 0.28 & 15.8 & 0.976 & 138 & 11.8 & 8.2 & 125 & 1.02 \\
\hline Oturere & 4 & 0.42 & 9.4 & 0.859 & 112 & 10.2 & 8.6 & 131 & 0.59 \\
\hline Makomiko & 3 & 0.13 & 5.3 & no data & 27 & 11.3 & 7.5 & 107 & 0.07 \\
\hline Makotuku & 2 & 0.13 & 5.7 & no data & 30 & 9.2 & 7.4 & 116 & 0.03 \\
\hline Waiharakeke & 3 & 0.23 & 3.5 & 0.965 & 159 & 10.7 & 8.1 & 104 & 0.01 \\
\hline Mangahuia & 2 & 0.20 & 8.6 & no data & 38 & 9.9 & 7.1 & 147 & 0.01 \\
\hline Poutu & 5 & 0.44 & 7.7 & 1.053 & 71 & 10.6 & 8.0 & 80 & 0.00 \\
\hline Orautoha & 3 & 0.24 & 2.5 & 0.548 & 128 & 12.8 & 8.3 & 166 & 0.00 \\
\hline Pukeonake & 4 & 0.17 & 6.8 & 0.398 & 23 & 8.2 & 7.0 & 158 & 0.00 \\
\hline \multicolumn{10}{|l|}{ Mt. Egmont } \\
\hline Waiwhakaiho & 3 & 0.25 & 13.8 & 0.614 & 109 & 16.6 & 7.9 & 100 & 50.00 \\
\hline Timaru & 2 & 0.12 & 3.6 & 0.295 & 69 & 14.6 & 6.9 & 213 & 34.04 \\
\hline Kaiauahi & 3 & 0.17 & 11.8 & 0.756 & 159 & 17.5 & 7.9 & 172 & 26.68 \\
\hline Manganui & 2 & 0.15 & 14.7 & 1.022 & 56 & 18.9 & 6.7 & 142 & 20.77 \\
\hline
\end{tabular}




\begin{tabular}{|l|r|r|r|r|r|r|r|r|r|}
\hline Waiongana & 2 & 0.13 & 8.9 & 0.684 & 112 & 15.6 & 7.7 & 164 & 17.74 \\
\hline Kapuni & 3 & 0.14 & 10.7 & 0.649 & 61 & 14.2 & 7.2 & 82 & 14.46 \\
\hline Punehu & 4 & 0.21 & 4.9 & 0.706 & 98 & 13.4 & 7.7 & 77 & 11.91 \\
\hline Mangorei & 2 & 0.12 & 6.2 & 0.715 & 82 & 15.2 & 7.3 & $>300$ & 10.07 \\
\hline Katikara & 2 & 0.11 & 2.6 & 0.403 & 55 & 15.5 & 6.8 & 168 & 8.81 \\
\hline Waiaua & 3 & 0.16 & 6.7 & 0.727 & 130 & 11.9 & 7.7 & 50 & 8.36 \\
\hline Oakura & 3 & 0.14 & 7.8 & 0.412 & 77 & 14.0 & 7.2 & 239 & 3.14 \\
\hline Kiri & 3 & 0.17 & 7.9 & 0.647 & 51 & 17.0 & 7.2 & 159 & 2.60 \\
\hline Waiaua Forks & 3 & 0.14 & 6.5 & 0.890 & 124 & 10.7 & 7.7 & 146 & 1.63 \\
\hline Kaupokonui & 3 & 0.18 & 7.4 & 0.580 & 79 & 18.1 & 7.5 & 150 & 1.56 \\
\hline Oaonui & 2 & 0.12 & 5.1 & 0.796 & 102 & 13.7 & 8.0 & 73 & 1.06 \\
\hline Cold & 1 & 0.21 & 3.4 & 0.797 & 80 & 10.0 & 7.3 & 74 & 0.98 \\
\hline Patea & 3 & 0.21 & 8.4 & 0.486 & 72 & 12.3 & 7.0 & 192 & 0.31 \\
\hline Waiaua trib. & 3 & 0.19 & 4.3 & 0.751 & 113 & 11.0 & 7.5 & 133 & 0.02 \\
\hline
\end{tabular}


Table II. Assessed properties of the channel, banks and riparian environment potentially related to bed stability, categorical variables were rated at a scale from 1 (associated with stable substrate) to 4 (associated with substrate instability), * variable removed because of intercorrelation.

\begin{tabular}{|c|c|}
\hline variable & description \\
\hline \multicolumn{2}{|c|}{ Riparian environment } \\
\hline A11 & Fraction of pasture on riparian strip (\%) \\
\hline A12 & Fraction of native forest on riparian strip (\%) \\
\hline A13 & Fraction of exotic vegetation on riparian strip (\%) \\
\hline A14 & Fraction of scrub on riparian strip (\%) \\
\hline A15 & Fraction of other land cover (none, tussock, etc.) on riparian strip (\%) \\
\hline A21 & Ratio of floodplain width to active channel width $(\mathrm{m} / \mathrm{m})$ \\
\hline $\mathrm{A} 22 *$ & Ratio of floodplain width to wet channel width $(\mathrm{m} / \mathrm{m})$ \\
\hline A23 & Ratio of active channel width to wet channel width $(\mathrm{m} / \mathrm{m})$ \\
\hline A31 & Percentage of high bank surface covered with vegetation $(\%)$ \\
\hline A32 & Variation in species and age of high bank vegetation (categorical) \\
\hline \multicolumn{2}{|c|}{ Channel cross profile } \\
\hline B11 & Channel incision, ratio of width to depth $(\mathrm{m} / \mathrm{m})$ \\
\hline B21 & Bank erosion (categorical) \\
\hline B22 & Number of recent bank collapses \\
\hline B31 & Number of recently deposited lateral bars of fine material (< coarse gravel) \\
\hline \multicolumn{2}{|c|}{ Channel longitudinal profile } \\
\hline C11 & Bed slope $(\mathrm{m} / \mathrm{m})$ \\
\hline $\mathrm{C} 21$ & Sinuosity (categorical) \\
\hline \multicolumn{2}{|c|}{ Channel bottom } \\
\hline D11 & Fraction of area affected by erosion and deposition (\%) \\
\hline D21 & Occurrence and form of aquatic vegetation (categorical) \\
\hline D31 & Number of multiple barforms \\
\hline D32 & Fraction of area occupied by multiple barforms $(\%)$ \\
\hline D41 & Number of riffle-pool and step-pool sequences \\
\hline D51 & Occurrence of bedform clusters (categorical) \\
\hline D61 & Fraction of area with supercritical flow (\%) \\
\hline \multicolumn{2}{|c|}{ Substrate } \\
\hline E11 & Grain angularity (categorical) \\
\hline E21 & Constitution of grain surface (categorical) \\
\hline E31 & Interlock and overlap between particles (categorical) \\
\hline E41 & Packing and compaction of particles (categorical) \\
\hline E51 & Fraction of sand and smaller grain size (\% area) \\
\hline E52 & Fraction of gravels (\% area) \\
\hline E53 & Fraction of cobbles (\% area) \\
\hline E54 & Fraction of boulders (\% area) \\
\hline E55 & Homogeneity (\% area of most abundant size class/ number of size classes present) \\
\hline E56* & Size index (Sum of fractions weighted by their geometrical mean size of their size class) \\
\hline E57* & Mean size index (Size index/ number of size classes present) \\
\hline E58* & Fraction of cobbles and gravels (\% area) \\
\hline E61 & Fraction of stable material (large boulders and bedrock) (\%) \\
\hline E71 & Occurrence of an armour layer (categorical) \\
\hline
\end{tabular}


Table III. Correlation of bed stability measurements (total tracer movement - TTM, bottom component Pfankuch Index - BCP), measured (marked with *) environmental parameters and periphyton biomass and downstream variables, segment variables and runoff-weighted upstream catchment variables from the FWENZ database (Wild et al., 2005) with NMDS axes, significant correlations are marked bold $(\mathrm{p}<0.01)$.

\begin{tabular}{|c|c|c|}
\hline Axis & 1 & 2 \\
\hline & Pearson's R & Pearson's R \\
\hline Width* & -0.06 & 0.06 \\
\hline Depth* & 0.33 & -0.20 \\
\hline Velocity* & 0.12 & -0.19 \\
\hline Conductivity* & 0.22 & -0.03 \\
\hline Temperature* & -0.17 & 0.13 \\
\hline $\mathrm{pH}^{*}$ & 0.33 & -0.09 \\
\hline Riparian Pasture* & 0.18 & 0.25 \\
\hline Riparian bare floodplain* & -0.44 & -0.33 \\
\hline Periphyton biomass* & 0.44 & 0.13 \\
\hline Average slope of downstream network & -0.31 & 0.09 \\
\hline Maximum slope of downstream segments & 0.18 & -0.10 \\
\hline Maximum segment slope based on $30 \mathrm{~m}$ grid & 0.03 & 0.17 \\
\hline Segment sinuosity & -0.05 & 0.07 \\
\hline Average segment slope & -0.26 & -0.12 \\
\hline Shaded fraction of segment & -0.02 & 0.06 \\
\hline Percentage of the segment riparian area covered in scrub & 0.20 & 0.13 \\
\hline Upstream mean January air temperature & 0.06 & $\mathbf{0 . 4 9}$ \\
\hline Upstream catchment rain days $>15 \mathrm{~mm} / \mathrm{month}$ & -0.27 & 0.13 \\
\hline Upstream lake index & 0.19 & 0.00 \\
\hline Percentage of upstream catchment annual runoff from alluvium & 0.12 & 0.13 \\
\hline Percentage of upstream catchment annual runoff from peat & -0.12 & -0.03 \\
\hline Upstream average of calciferous regolith & -0.19 & 0.14 \\
\hline Upstream catchment average of regolith hardness & -0.10 & -0.06 \\
\hline Upstream catchment average of particle size & -0.05 & 0.04 \\
\hline Percentage of upstream catchment consists of bare ground & 0.15 & -0.62 \\
\hline Percentage of upstream catchment covered in exotic forest & 0.25 & -0.10 \\
\hline Percentage of upstream catchment covered in indigenous forest & -0.08 & 0.39 \\
\hline Percentage of upstream catchment with pastoral landuse & 0.17 & 0.09 \\
\hline Percentage of upstream catchment covered in tussock & -0.04 & -0.25 \\
\hline Percentage of upstream catchment consist of wetland & 0.10 & 0.10 \\
\hline Segment stream order & 0.18 & -0.02 \\
\hline TTM & -0.53 & 0.04 \\
\hline $\mathrm{BCP}$ & -0.57 & 0.09 \\
\hline
\end{tabular}


Table IV. Results of the regression analysis of the NMDS axis against 39 characteristics of the channel and the riparian environment $\left(R^{2}=0.805\right.$, adjusted $R^{2}=$ 0.726), VIF - variance inflation factor.

\begin{tabular}{|l|r|r|r|r|r|}
\hline Variables & Coefficient & Std error & T-test if slope $\neq 0$ & P value & VIF \\
\hline Constant & -6.31006 & 1.00297 & -6.29 & 0 & 0 \\
\hline A23 & 0.21652 & 0.06028 & 3.59 & 0.0011 & 2.1 \\
\hline A31 & 0.01239 & 0.00375 & 3.31 & 0.0023 & 1.8 \\
\hline B21 & 0.26123 & 0.06495 & 4.02 & 0.0003 & 2 \\
\hline C11 & 0.05583 & 0.02096 & 2.66 & 0.012 & 1.3 \\
\hline D11 & 0.29004 & 0.09619 & 3.02 & 0.005 & 3.2 \\
\hline D31c & 0.28711 & 0.07222 & 3.98 & 0.0004 & 3 \\
\hline D32 & 0.012 & 0.00556 & 2.16 & 0.0385 & 1.9 \\
\hline D51c & 0.27049 & 0.07771 & 3.48 & 0.0015 & 1.6 \\
\hline E11 & 0.2418 & 0.12253 & 1.97 & 0.0572 & 1.5 \\
\hline E21 & 0.16677 & 0.09457 & 1.76 & 0.0874 & 2.6 \\
\hline E41 & 0.25041 & 0.11964 & 2.09 & 0.0444 & 1.7 \\
\hline E51 & 0.02885 & 0.00937 & 3.08 & 0.0042 & 2.2 \\
\hline E55 & 0.0524 & 0.02019 & 2.6 & 0.0141 & 3.1 \\
\hline
\end{tabular}

Table V. Correlation of invertebrate community metrics with bed stability assessed with the SBSI protocol, in situ marked tracer stones (TTM) and the bottom component of the Pfankuch Stability Index (BCP) at 46 New Zealand streams used for SBSI calibration and at 8 independent sites from the same regions for validation. Significance from multiple correlations was adjusted using False Discovery Rate and is indicated by $*$ for $\alpha=0.05$, ** for $\alpha=0.005$ and $* * * \alpha=0.001$.

\begin{tabular}{|l|l|l|l|l|l|l|l|}
\hline & \multicolumn{3}{|l|}{ SBSI calibration sites } & & \multicolumn{3}{l|}{ Validation sites } \\
\hline & SBSI & TTM & BCP & & SBSI & TTM & BCP \\
\hline Brillouin Index & $-0.75^{* * *}$ & $-0.52^{* * *}$ & $-0.68^{* * *}$ & & $-0.81^{*}$ & $-0.78^{*}$ & $-0.73^{*}$ \\
\hline Taxa number & $-0.56^{* * *}$ & -0.27 & $-0.54^{* * *}$ & & $-0.73^{*}$ & -0.34 & $-0.82^{*}$ \\
\hline $\begin{array}{l}\text { Rarefied taxa number for } \\
\text { 200 individuals }\end{array}$ & $-0.77^{* * *}$ & $-0.51^{* * *}$ & $-0.55^{* * *}$ & & $-0.73^{*}$ & -0.40 & $-0.82^{*}$ \\
\hline $\begin{array}{l}\text { Mean number of } \\
\text { individuals }\end{array}$ & $-0.75^{* * *}$ & $-0.35^{*}$ & $-0.45^{* *}$ & & $-0.74^{*}$ & -0.34 & $-0.86^{*}$ \\
\hline
\end{tabular}


Table VII. Parameters of the stream Bed Stability for Invertebrates (SBSI) survey with weights and potential range of values (*extreme values estimated) and scores.

\begin{tabular}{|l|l|l|l|l|l|}
\hline & Parameter & Weight & Range & $\begin{array}{l}\text { Minimum } \\
\text { score }\end{array}$ & $\begin{array}{l}\text { Maximum } \\
\text { score }\end{array}$ \\
\hline C11 & Bed slope & 0.56 & $0.0001^{*}-1^{*}$ & 0.00006 & 0.56 \\
\hline A23 & Active /wet channel & 2.17 & $1-10^{*}$ & 2.17 & 21.7 \\
\hline B21 & Bank erosion & 2.61 & $1-4$ & 2.61 & 10.44 \\
\hline A31 & Bank vegetation cover & 0.12 & $0-100$ & 0 & 12 \\
\hline E51 & Sand fraction & 0.29 & $0-100$ & 0 & 29 \\
\hline E55 & Substrate homogeneity & 0.52 & $4-100$ & 2.08 & 52 \\
\hline E41 & Packing and compaction & 2.50 & $1-4$ & 2.50 & 10.0 \\
\hline E21 & Particle surface & 1.67 & $1-4$ & 1.67 & 6.68 \\
\hline E11 & Grain angularity & 2.42 & $1-4$ & 2.42 & 9.68 \\
\hline D11 & Reworked area & 2.90 & $1-4$ & 2.90 & 11.60 \\
\hline D31 & Multiple barform number & 2.87 & $0-5$ & 0 & 14.35 \\
\hline D32 & Area of multiple barforms & 0.12 & $0-100$ & 0 & 12 \\
\hline D51 & Bedform clusters & 2.70 & $1-4$ & 2.70 & 10.80 \\
\hline & Total SBSI & & & 19.05 & 200.81 \\
\hline
\end{tabular}
tracer stones (TTM) and the bottom component of the Pfankuch Stability Index (BCP) at 46 New Zealand streams used for SBSI calibration and at 8 independent sites from the same regions for validation. Significance from multiple correlations was adjusted using False Discovery Rate and is indicated by * for $\alpha=0.05$, ** for $\alpha=0.005$ and $* * * \alpha=0.001$.

\begin{tabular}{|l|l|l|l|l|l|}
\hline \multicolumn{2}{|l|}{ SBSI calibration sites } & & \multicolumn{2}{l|}{ Validation sites } \\
\hline & TTM & BCP & & TTM & BCP \\
\hline SBSI & $0.48^{* * *}$ & $0.66^{* * *}$ & & 0.47 & $0.75^{*}$ \\
\hline BCP & $0.46^{* *}$ & & & 0.67 & \\
\hline
\end{tabular}


Figure 1. Stream reaches in the southern North Island of New Zealand studied for calibration of the Stream Bed Stability for Invertebrates protocol. Open circles denote the sites used for validation.

Figure 2. Non-metric Multidimensional Scaling axes of 46 mountain stream invertebrate communities and correlated parameters $(\mathrm{p}<0.01)$. Periphyt - periphyton biomass, usAveTWar - Upstream mean January air temperature, usIndigF Percentage of upstream catchment covered in indigenous forest, TTM - total tracer movement, BCP - bottom component of Pfankuch Index, RipBareF - Dry active channel bare of vegetation under base flow conditions, usBare_q - Percentage of upstream catchment consisting of bare ground.

Figure 3. Stream bed stability assessed with the Stream Bed Stability for Invertebrates Index (SBSI), in situ marked tracer stones (TTM) and the bottom component of the Pfankuch Stability Index (BCP) plotted against the NMDS axis used for calibration of the SBSI.

Figure 4. Site scores of the Stream Bed Stability for Invertebrates Index (SBSI) plotted against conventional measures of bed stability: In situ marked tracer stones (TTM, closed symbols) and the bottom component of the Pfankuch Stability Index (BCP, open symbols). Sites used for validation are shown as triangles. 
Figure 1. Stream reaches in the southern North Island of New Zealand studied for calibration of the Stream Bed Stability for Invertebrates protocol. Open circles denote the sites used for validation. $150 \times 120 \mathrm{~mm}(600 \times 600 \mathrm{DPI})$ 


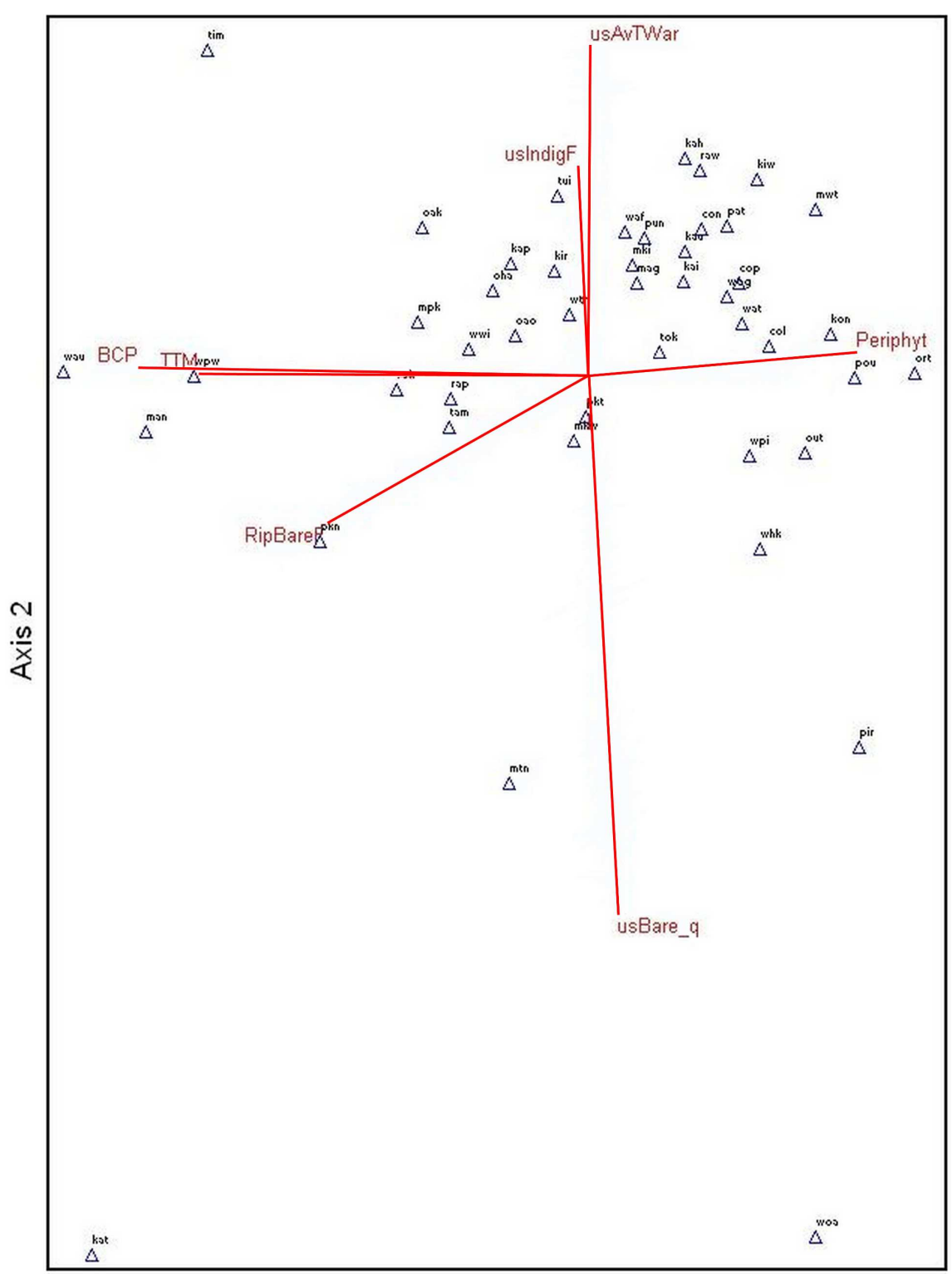

Axis 1

Figure 2. Non-metric Multidimensional Scaling axes of 46 mountain stream invertebrate communities and correlated parameters $(p<0.01)$. Periphyt - periphyton biomass, usAveTWar Upstream mean January air temperature, usIndigF - Percentage of upstream catchment covered in indigenous forest, TTM - total tracer movement, BCP - bottom component of Pfankuch Index, RipBareF - Dry active channel bare of vegetation under base flow conditions, usBare_q - Percentage of upstream catchment consisting of bare ground. $164 \times 225 \mathrm{~mm}(600 \times 600 \mathrm{DPI})$ 


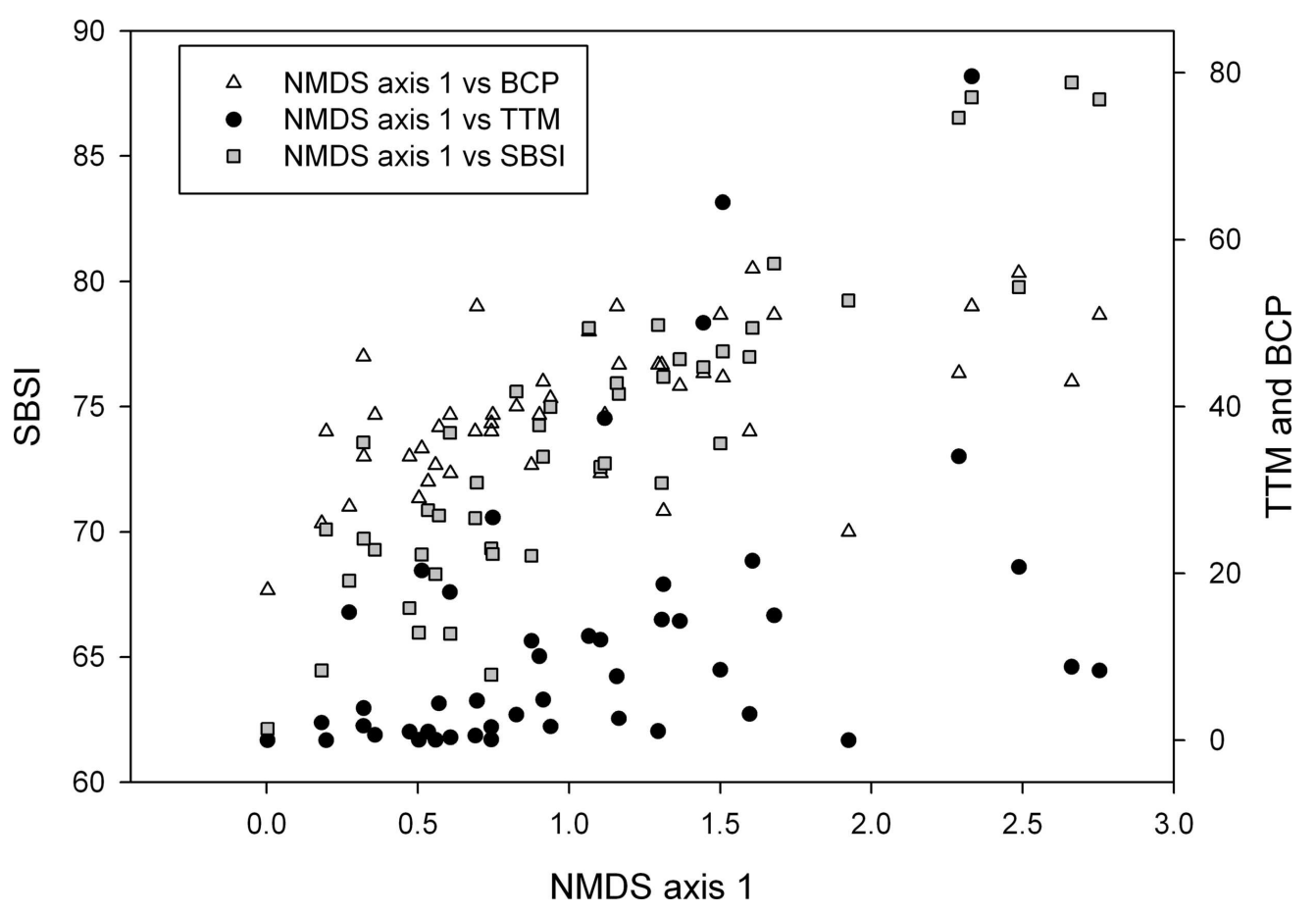

Figure 3 Stream bed stability assessed with the Stream Bed Stability for Invertebrates Index (SBSI), in situ marked tracer stones (TTM) and the bottom component of the Pfankuch Stability Index (BCP) plotted against the NMDS axis used for calibration of the SBSI. $105 \times 72 \mathrm{~mm}(600 \times 600 \mathrm{DPI})$ 
Figure 4 Site scores of the Stream Bed Stability for Invertebrates Index (SBSI) plotted against conventional measures of bed stability: In situ marked tracer stones (TTM, closed symbols) and the bottom component of the Pfankuch Stability Index (BCP, open symbols). Sites used for validation are shown as triangles. $105 \times 72 \mathrm{~mm}(600 \times 600 \mathrm{DPI})$ 